it is to be hoped, will in time shrink to smaller dimensions. Vision is still rather better in the left eye than the right. The long torpidity of the retina of the right, from deprivation of its proper stimulus, may account for this fact. We may reasonably hope that in both eyes an improvement of sight will continue to take place, as exercise, and, if we may so speak, education, developes their dormant capabilities. But on the other hand it is scarcely probable that eyes so much less than the standard dimensions can possess the full degree of power of vision which belongs to the perfectly-developed organ.

The results of the operations must be regarded as eminently satisfactory, since, though performed under circumstances greatly enhancing the difficulties of their execution, the success has been nearly perfect. Were the organs otherwise competent to the fulfilment of their function, the slight opacity remaining in the left pupil would be no serious obstacle.

The boy was advised to return to the country for the summer, and to devote his attention to out-of-door pursuits, rather than to make frequent attempts to exercise his sight upon minute objects. Such a course will probably enhance his visual power, which may afterwards be applied with more advantage to pursuits requiring closer observation.

['I'o be continued.]

\title{
DR. LEONARD ON THE DIFFERENT VARIETIES OF DIARRIOAA.
}

[Concluded from prage 406.]

(k) Cholera Infantum, or the chronic cholera of infants, is another diarrhœea common to the Now England and middle States during the summer and autumn. The season is now fast approaching when this formidable disease will be prevalent, and the connecting link of many a young and interesting family circle will be snapped asunder, and the tenderest and inuch-loved one consigned to the shades of death. There will be no power to avert, no skill to save, in many instances of this most intractable scourge. It is somewhat allied to lienteria, though it is evidently a species of cholera.-(Maunsell and Evanson.)

"Cholera infantum is a disease indigenous to this country. It prevails every year, as an endemic, in all the large cities throughout the middle and southern, and most of the western States, during the season of the greatest heat." - (Condie.)

This disease may terminate in health in a short time, or it may tet minate fatally in a few hours. A great many cases become chronic and continue for weeks or months. It is most frequently met with in large cities and marshy districts. Very young children are not liable to it, nor those who have passed over the third year of life. During dentition and nursing there is an increased liability to it. Children that nurse too long are apt to have this form of "summer complaint." "Irritating and inappropriate articles of food are at all times apt to produce disorders of the stomach and bowels, and when the system is predisposed to affections of this kind, by the causes mentioned above, slight errors,

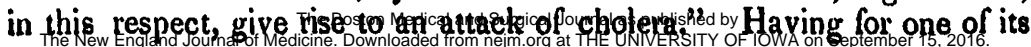
For personal use only. No other uses without permission. From the NEJM Archive. Copyright @ 2010 Massachusetts Medical Society 
causes a bigh degree of atmospheric temperature, and its development being fitvored by density of population, and miasma, this disease is found to prevail in the lanes and alleys of larere towns among the destitute; yet no class of socicty is exempt from it, from the lowest grades to the hightest ranks in the community.

Its first symptoms are diarhoea and vomiting ; there will be considerable febrile disturbance, coldness of the feet and hancis, a death-like expression of the countenance, and indications of pain. The matter vomiterl is of all colors; is green or light, dark or blackish-the dejections are milky, turbid and offensive. As the complaint progresses, the symptorns become less acute, the skin is hot and diy, vomiting less fiequent, scantiness of urine, the stools of all shades and hues-white, green, chrome color, curd-like, yellow and tinged with blood-and the diarmoa continues. At this period the tongue is dry, and aphtha, cedema and petechix are seen. Iastly, there is emaciation, drowsiness, difficult deglutition, rigidity, paralysis, convulsions and death.

Its chief anatomical characters are an undue development of the follicles of the stomach and bowels, inflammation and softening of the mucous membrane of the stomach and large intestine, ulceration of the follicles, other organs and parts being involved, as the liver, lungs, and lastly the brain, which becomes softened, its membranes inflamed, and there is "effusion in the sub-arachnoid tissue."-(Hallowell on Endemic Gastro-follicular Enteritis-Amer. Jour. of Medical Sciences for July, 1847.)

Such, then, are its symptoms and morbid anatomy. Its treatment must depend upon the stage of the disease and the morbid condition existing. To allay irritation and vomiting, some mild stimulating application may be put over the stomach, as a mustard or ginger poultice, the first being tempered to the case, and the latter mixed with an equal part of meal. They should not be kept on ton long, but may be removed from time to time as circumstances require. A few drops of tinct. opii may then be given in a weak solution of the bi-carbonate of potash-or a little tinc. of ginger or ess. of spearmint may be administered in the chalk mixture. If the vomiting still persists, a drop of creosote may be given every half hour until nausea ceases. Dr. Condie says, "when everything else fails, we believe that we shall be seldom disappointed in allaying the gastric irritability by the prescription of a teaspoonful, every hour or two, of the following solution :"-R. Aquæ puræe, $z_{\mathrm{j}}$.; acetat. plumbi, gr. v. ; sacch. alb., 3 iij. $\mathbf{M}$.

If inflammatory action is established, it must be counteracted by leeches over the stomach or abdomen; and mercurials, aconite and nitre may be employed very cautiously till it be subdued. To restrain the diarrhœa during the acute stage, small doses of Dover's powder or some other opiate, with or without lead, may be tried, and if they fail, enemata of laudanum and starch can be had recourse to. Farther on in the disorder, we may try strychnine, catechu, kino, spiræa, tannic acid, \&c., in connection with alterative remedies. Lastly, stimulants and tonics are required to sustain the patient and to prevent effusion fromi exhaustion.

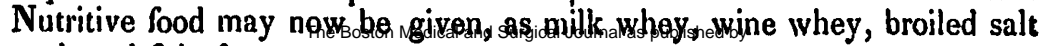

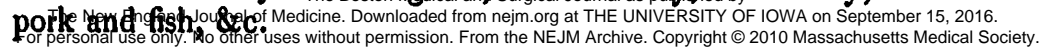


It is indispensable in this form of diarrhea, as well as in all others, that the patient be kept quiet, at perfect rest, and that cleanliness be scrupulously observed in the sick room. The clothing, the bed, and everything which relates to the sick, should be kept in the nentest manner. There should be free ventilation above all things else, for without this we can hardly expect any benefit from other treatment. Wet and filthy cloths, or clothing left in contact with the patient's body, induce purging in some way; call it sympathy, or anything else, it is certain that such an effect is produced, and therefore the exposure ought to be avoided on this account, if on no other.

The saline treaiment here, or the use of salted provisions, bears a nearer relation to the employment of salt in malignant cholera than in other forms of bowel conplaints. Here the analogy is truly "striking," and suggests the adoption of it in cholera infintum, and 1 would recommend a trial of Dr. Stevens's prescription in the latter disease. " $R$. Sodæ sesquicarb., $Э$ j. ; sodii chlorid., 3 j.; potass chloratis, gr. vij. Misce." Dissolve in half a tumbler of cold water, and give a teaspoonful every fifteen or thirty minutes till re-action takes place, then give two drachms once in four hours. Speaking of its use in cholera, Dr. Stevens observes, "when the stomach is very irritable, the use of the saline powder may be occasionally suspended, and common effervescing mixtures, or small doses of cornmon soda powders, with an excess of the carbonates, used until vomiting abates, and then the carbonate of soda, with larger doses of the chlorate of potash, may be given by itself, in doses of ten grains each." Of course, this treatment is most applicable to the first stages of the complaint, but I am inclined to think that the chloride of soda is capable of doing great good throughout its entire progress, upon the principles I have attempted to establish.

"In the chronic form of the disease, however, beef tea, or weak chicken broth, sometimes produces a favorable change in the state of the stomach. In cases of this kind, the patient manifests a most urgent craving for certain strong and stimulating articles of food, such as salted and smoked herring or shad, old and rancid bacon, salted beef, \&c., while the stomach appears to loathe all the light and unirritating articles of nourishment. When this occurs, it will be proper to cautiously gratify the newly-awakened appetite, however opposed to the ordinary rules the indulgence may appear to be." "I lave seen many children recover," says Dr. Rush, "from being gratified in an inclination to eat salted fish, and the different kinds of salted meat."-(Vid. Eberle's Treatise on Children, page 297.) I had a litule patient, in the autumn of 1845, who bad a peculiar relish for fat roasted meat and beef steak. He was allowed to indulge his appetite, and recovered from a very low state without much medicine, save opiates. He had been ill for nearly two months, when this dietetic course was resorted to with the happiest effects. These patients sometimes hanker for butter as well as fat meats, and eat it with advantage. This indicates the necessity of oils to supply the waste which is continually going on in cholera infantum.

(I) Cholera Morbus, sporadic cholera, English cholera, passio chole-

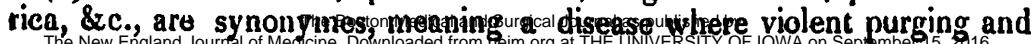
For personal use only. No other uses without permission. From the NEJM Archive. Copyright @ 2010 Massachusetts Medical Society. 
vomiting are the leading symptoms. The disease may be preceded by colicky pains, nausea, a sensation of fulness of the bowels, rigors, \&c., or it may come on suddenly with cramps and spasms.

It has for its cause, hot weather, it being peculiar to our summers and autumns and to hot climates. It is common to travellers over the Isthmus of Panama, and through Mexico, and the natives of those countries are also sulject to it. Any irritant influence upon the stomach or nervous system may produce it-as fear, grief, crude fruits, unwholesome food, or too much matter in the stomach. The complaint was very prevalent at San Francisco and Sacramento city last summer and fall. At the latter place I observed that there was scarcely any time of night, but that the distressing groans of some one in pain, retching, vomiting, \&c., could be heard, which really rendered the nights gloomy and dismal. Near to every tent and domicile these scenes were hourly and nightly witnessed. In hot countries it is more fatal than with us. At Panama I knew a stout healthy man eat freely of pine apples and other fruir, and die of cholera morbus in a few hours. Many of our people have lost their lives by indulging in such imprudencies, since the Isthmus and Mexico have become thoroughfares to the new El Dorado. Intemperance in wine and other liquors is another cause of cholera morbusso is the eating of shell fish, the drinking of bad water, or taking too much drink of any sort.

The cure consists in avoiding the causes as much as possible, allaying the vomiting, purging and irritation, and in quieting the pain and restoring strength. 1. See that the patient shuns all external causes and adopts a proper regimen. 2. Apply sinapisms to the feet and over the stomach, and give morphia and peppermint in a solution of the bi-carbonate of potash to arrest vomiting, purging and irritation. This is when the matter ejected is green and bilious; but if it happens, as it sometimes does, that the stools and matter vomited are light colored, small doses of calomel and morphia will be best, until the bilious hue is restored to the alvine evacuations. 3. Opiates and stimulants should be continued till pain abates and the patient becomes refreslied, afterwards the patient is to be trusted to a mild but nourishing diet, and tonics, like quinine, quassia, gentian, \&c.

1 do not approve of the practice of provoking emesis and catbarsis by any means whatever; for generally this will go to excess of itself-in fact, these two actions in excess constitute the disease. There is no such thing as cholera morbus without violent vomiting and purging. Then why aggravate and make worse that which we should quiet and restore? If a person be just attacked, and we have renson to suppose that there are substances in the stomach which irritate, some bitter infusion like green tea may be given till gentle emesis is induced. Purges are never admissible during the earlier stages of the disorder.

(m) Cholera Maligna, or epidemic cholera, is a disease well known to the readers of this Journal, though not so frequent and constant as most of the other species of bowel complaints attended with diarrhœa which I have glanced at in this essay. It differs remarkably from

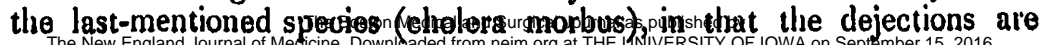


generally light colored, like rice water, and contain no bile. They may be bloody, and are astonishingly profuse-the cramps are more severethen there is the stage of collapse, blueness of the skin, corrugation, the vox cholerica, and the consecutive fever, which do not belong to any disease but the Asiatic cholera.

Much has been written upon cholera-upon its nature, causes, pathology and treatment. I shall not attempt to add anything in this way more than to say a very few words. From what $I$ know of the complaint, I am led to think that it is not contagious; but it may become infectious under certain circumstances. I believe it to depend upon "epidemic influence," whenever it merits the term epidemic cholera. (Vid.my paper "On Epidemic Influence," Boston Med. and. Surg. Jour. for June 28, July 5 and July. 12, 1848.) When this influence is in operation, the passions of the mind particularly predispose to the development of the poison-and undoubtedly many imaginary cases of cholera occur.

Mr. B. consulted me while on the "istlumus," last May, saying that he thought that he had cholera. After examining his cise, I informed him that he was mistaken, that he was not even sick. In the course of a few hours he sent for me in great haste, the messenger saying that B. had "got the cholera the worst kind." I found him free from all choleric symptoms; he had not got diarrhœa. He fancied, however, that he had "cramps." I thought it best to treat him for cholera! I told him I should give.some "cholera pills" which would cure him very quick. I sent him some brcad pills, one to be taken every thirty minutes till symptoms improved, \&c. He was well the next morning. After the subsidence of the cholera panic at Panama, I told him what those cholera pills were made of. He would not believe me at first, but when he saw that I was in earnest, he went away mortified and chagrined ut his own folly. From this case, and from thousands like it, we infer that persons may worry themselves into disease, and that unless we can control the minds of such patients we shall not be likely to do them the least good. I have no doubt that many of the cholera cases reported to have been cured "homocopathically" were of this character, where the distemper was located in the "spiritual essence" of the patient's mind, and not in the vital parts of the body.

Epidemic cholera manifests a partiality for particular locations, as experience and its history show. It has never prevailed on the Pacific side of this Continent, though it has raged with fearful strides in the same latitudes in the interior and on the Atlantic. Now diarrhoa is an endemic disease, prevailing at all seasons on the Pacific coasts from Chili to Oregon, in every port; yet it is a singular fact that cholera maligna bas never invaded the Pacific shores.* Now whether the endemic influences which produce diarrhoea are such as in some way to

\footnotetext{
* Dr. Harris, formerly of New York, but uow of San Francisco, late Healtin Officer at the port of New York, in a leller to Dr. Vache, relates nearly the same circumstances relative to the cholern, and its appearance at Panama in 1849 , ns are contained in my letter loce referred to. The leter of Dr. If. was published the 17th of May, in the Nrw Tonk Lien. In concluding,

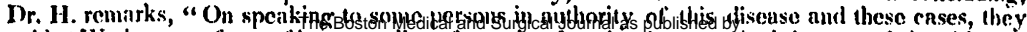

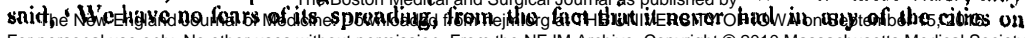
For personal use only. No other uses without permission. From the NEJM Archive. Copyright @ 2010 Massachusetts Medical Society.
} 
destroy the epidemic poison of cholera, is more than I dare venture to assert or attempt to explain. 1 merely state the facts, and leave it to other's to theorize and speculate as the weight of evidence may preponderate in the scales of opinion.-(Vid. my letter from Panama, Boston Med. and Surg. Jour. for July 11th, 1849.)

(n) Mental Diarrhaa inay, and does, assume any form and resemble either species of bowel complaint. It may be acute or chronic; depending upon the nature of the mental cause, whether it be transient or permanent in its duration. And as 1 have said, the flux may be bilious, mucous, lienteric or choleric in its character. As sudden excitement induces disease through the influence of nervous action, so does the impression which is more durable and long-continued exert its deleterious effect upon the animal economy.

I have, within a few years, had a young woman under my charge, who has suffered from the most obstinate diarrhœa that I ever knew to exist without destroying life. The complaint assumed every type and resisted all treatment-pills of opium, and lead and opium, and the sulph. of copper with opium, would only control the flux in a molerate degree. My patient became feeble, emaciated and neuralgic. She had, previously to being attacked with the bowel complaint, been seduced by her faitbless lover. I at length conceived that her troubles, grief and disgrace were the exciting causes of her disense. I reasoned with her, endeavoring to soothe her mind, and I secured the coöperation of some of her own sex whose friendship and condolence she could value and rely upon; and it was under this kind of management that she was restored to a comfortable degree of health.

1 have been consulted in the case of an elderly woman, a native of England, whose fanily were mostly left belsind, and whose relatives who were in this country considered her rather a tax upon their generosity than a comfort to their houselsold, and whose circumstances were anything but cheering and prosperous. This old woman has a diarbea of a bilious cast, which is most severe. Some physicians have expressed it as their opinion that the complaint is kept up by some organic lesion. I at one time inclined to that opinion myself; but latterly, I am convinced that the mind is diseased, and its operation upon the nervous centres is the cause of the affection.

I became acquainted with a similar instance in California, in the case of a young man who had left a pleasant home and an interesting young wife, and met with disappointment in that country. I observed that in proportion as his mind was distuacted, in proportion as he allowed these things to worry and harass hin, accordingly would he suffer from the diarrbœa.

In managing any of the complaints which I have noticed, it is of great

the Pacific, nor on board of any vessel navignting its waters.' Now is this true, and if true will you please give ine your reasons when you reply to this ?"

Certainly there is a mystery about this, not yet explained. Such a rush of emigration as there was over the "isthmus," and along these shores, tho emigrants, or many of them, last season, loning from intereted distriets, and hatving the seeds of disease in them which were most fearfully

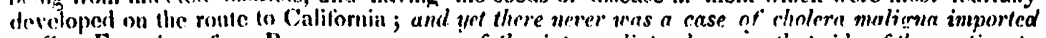

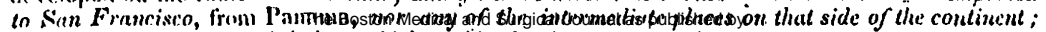

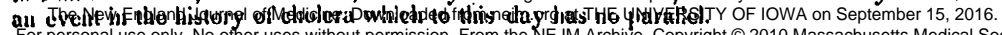


consequence and moment, that strict regimen, and rest of body and mind, be secured. Cathartics and emetics are likely to injure the delicate structures with which they come in contact, as well as to enfeeble and enervate the patient. All medication should have direct reference to the stage, to the pathology and type of the disorder. Age, sex, and all the conditions relating to the patient, will have more or less weight upon the mind of the physician (as these different circumstances may seem to have influence as predisposing and exciting causes). so that the treatment will in every respect correspond to the indications which are to be fulfilled.

J. P. Leonard, M.D.

Greenville, R. I., June, 1850.

\section{CHLOROFORM IN A CASE OP POISONING BY STRYCHNINE.}

To the Editor of the Boston Medical and Surgical Journal.

DEAR Sir,-The following I transmit to you, and if you think proper you are at liberty to insert it in your Journal.

Mr. G_- aged about 40, of intemperate habits, took, from among my medicines, on the 5th inst., a bottle of strychnine, and supposing it to be morphine, as he said, swallowed a dose supposed to be about one or two grains. In about twenty minutes afterwards I was requested to see him, as he was supposed to be in a "fit." I found him in the following condition. The whole muscular system rigid; the muscles of the back, and of the upper and lower extremities, rigidly contracted; the head drawn back; articulation difficult; sense of tightness about the chest, perspiration flowing profusely from the fuce and chest. A number of the physicians of the place came to his assistance. The usual remedies recommended in such cases were resorted to, but without any mitigation of the urgent symptoms. The patient was failing rapidly under the increasing spasmodic action of the whole muscular system. It was now determined to administer chloroform, as death was apparently certain without some relief. One drachmi of chloroform was put upon a silk handkerchief, and the patient directed to inhale it. The effect was decisive. The patient (who was at this time in a sitting posture, held so by assistants, who could not move him in the least degree without exciting the most frightful and alarming spasms) requested to be placed in a recumbent position, which was done without exciting the least spasm. The chloroforin was carefully administered for some hours, the patient holding the handkerchief most of the time himself, in order, as he said, " to keep off the dreadful spasms." From this time he recovered rapidly, and on the 7th inst. was able to leave for home, a distance of six or seven miles.

In the Western Lancet and Hospital Reporter for February, 1850, published at Cincinnati, Ohio, there is a similar case reported, which is the only one that I know of in which chloroform has been given in case of poisoning by strychnine. Is it not possible that chloroform is the remedy in such cases?

Respectfully yours, \&c. 